\title{
HLA-DRB1*1101 allele confer protection for Multiple Sclero- sis disease in Cuban population
}

\author{
Alelo HLA -DRB1*11:01 asociado con la Esclerosis Múltiple en población cu- \\ bana confiere protección \\ Fernández-de-Cossío ME, ${ }^{1 *}$ Cintado A, ${ }^{1}$ Nazabal M, ${ }^{1}$ Hanlet $C,{ }^{1}$ Díaz T, ${ }^{1}$ Villarreal A, ${ }^{1}$ Ale M,,${ }^{1}$ Grass $D,{ }^{2}$ Cervantes-Llanos $M,{ }^{1}$ \\ Pavon-Fuentes N, ${ }^{2}$ Benitez JV, ${ }^{1}$ Cabrera-Gomez JA, ${ }^{2}$ Diaz de la Fe A, ${ }^{2}$ Pentón-Rol G. ${ }^{1}$
}

*Maria Elena Fernández-de- Cossio and Alberto Cintado-Benitez contributed equally to this work.

ABSTRACT

DOI. $10.21931 / \mathrm{RB} / 2016.01 .04 .5$

Multiple sclerosis is a neuro-inflammatory autoimmune disease. The MHC class II region produces the strongest effect on Multiple Sclerosis genetic susceptibility. The purpose of this study is to evaluate DRB1*, DQA $1{ }^{*}$, and DQB1 ${ }^{*}$ alleles among Multiple Sclerosis Cuban patients. 100 patients and 200 unrelated healthy controls were included. Ancestry informative markers were used. Multiple Sclerosis associated HLA susceptibility/protection alleles were ascertained by PCR using specific primers. Statistical analyses were conducted using STRUCTURE 2.1, ADMIXMAP 3.7, SPSS 16.0 packages. Logistic regression analysis showed odds ratio of 5.7 for Multiple Sclerosis associated with a unit change in European admixture proportion. Evidence for susceptibility to Multiple Sclerosis was observed for the presence of HLA-DRB1*15, DRB1*14, DQA $1 * 01$ and DQB $1 * 06$ alleles, with odds ratio 3.40, 4.96, 2.53, and 2.77 respectively compared to healthy controls. A protective effect of HLA DRB $1{ }^{*} 01$, DRB $1 * 07, \mathrm{DRB} 1{ }^{*} 10$ was found among Multiple Sclerosis patients (odds ratio $0.35,0.2,0.4$ respectively). After correcting for admixture, a new association to HLA-DRB1*1101 was identified. Alleles HLA-DRB1*, DQ were associated with Multiple Sclerosis in Cuban patients. HLA-DRB1*1101-1104 was associated to Multiple sclerosis in this study sample, where the European ancestry proportion was identified.

Keywords: HLA-DR, HLA-DQ, Admixture, Multiple Sclerosis, Cuban population, AIM

\section{RESUMEN}

La Esclerosis Múltiple (EM) es una enfermedad autoinmune neuroinflamatoria. La región clase Il del Complejo Mayor de Histocompatibilidad $(\mathrm{CMH})$ produce el mayor efecto genético sobre la EM. El objetivo de este estudio es evaluar los alelos DRB1*, DQA1* y DQB1* en enfermos cubanos con EM. En el presente estudio se incluyeron 100 pacientes y 200 individuos no relacionados. Se emplearon Marcadores informativos de ascendencia. Se realizó la determinación de los alelos HLA, indicadores de protección-susceptibilidad, asociados con la EM mediante la reacción en cadena de la polimerasa y el uso de oligonucleóticos específicos. Los análisis estadísticos se desarrollaron con los paquetes estadísticos STRUCTURE 2.1, ADMIXMAP 3.7 y SPSS 16.0. El análisis de regresión logística mostró un valor de odds ratio de 5,7 para una asociación de la EM con la proporción de mezcla europea en una unidad de cambio. Los alelos HLA-DRB1*15, DRB1*14, DQA1*01 y DQB1*06, confieren susceptibilidad a la EM con valores de odds ratio de $3.40,4.96,2.53$, y 2.77 respectivamente. Un efecto de protección se observó para los alelos HLA DRB $1 * 01, \mathrm{DRB} 1$ *07, DRB $1 * 10$ con odds ratio de $0.35,0.2,0.4$ respectivamente. El alelo DRB1 ${ }^{*} 1101-1104$ se asoció a la EM en la muestra de estudio, donde se identificó la proporción de ascendencia europea.

Palabras clave: HLA-DR, HLA-DQ, mezcla genética, Esclerosis Múltiple, población cubana, marcadores informativos de ascendencia

\section{Introducción}

Multiple sclerosis (MS) is a chronic neuro-inflammatory autoimmune disease believed to arise from complex interactions of both environmental and genetic factors. A genetic contribution to the pathoge- nesis of MS had already been assumed in 1896 with the discovery of the familial aggregation of MS. ${ }^{1}$ The earliest association between genes and MS found in the Human leukocyte antigen ${ }^{2}$ (HLA) and described in 1972 at 6 p21 has long been recognized as the strongest locus increasing risk to MS in most populations, ${ }^{3}$ nota-

\footnotetext{
${ }_{1}^{1}$ Pharmacogenomics Department. Biomedical Research Division. Center for Genetic Engineering and Biotechnology, 31 entre 158 \& 190, Cubanacán, Playa, Cuba.

${ }^{2}$ International Center of Neurological Restoration. Ave 25 no 15805 entre 158 \& 160 Cubanacan Playa, Cuba.
}

Correspondence: email: mariaelena.fernandez@cigb.edu.cu 
bly HLADRB $1^{\star} 1501$ and other major histocompatibility complex (MHC) alleles. ${ }^{4}$

An association was seen for the $\mathrm{DRB} 1^{\star} 1501$ allele, as the main susceptibility allele in MS residing on a large, extended haplotype. ${ }^{5}$ This has been fine-mapped to the HLA-DRB5 ${ }^{\star} 0101$ DRB $1^{\star} 1501-\mathrm{DQA} 1^{\star} 0102-\mathrm{DQB} 1^{\star} 0602$ extended haplotype in the Northern European population with estimated risk ratios of approximately 3 , and homozygozity for this haplotype increases MS risk sixfold. ${ }^{6}$

The overall prevalence of MS is about 70 per 100,000 individuals (range from 2 to 150). ${ }^{7}$ The first case of MS in Cuba was published in 1965. After 1990, the prevalence of clinically-definite MS in the different Cuban provinces was around 10 per 100,000. The latest study, in Cienfuegos province, ${ }^{8}$ provides a prevalence of 25.5 per 100,000 .

MS has been reported in all continents in different populations. Of these, Europe is considered a high prevalence region for MS ( $\geq 30 / 100000)$ and different attempts are undergoing to evaluate how the risk of MS varies among European populations. ${ }^{9}$ Brum et al., have defined that MS presents a high prevalence rate, particularly in white persons from Western countries when patients from Brazil were analyzed. ${ }^{10}$

Cintado et al., have stated a population structure in a multiethnic Cuban population from Havana City and they have reported that $85 \%$ are of Spanish descent and the African contribution is of $15 \%$ suggesting that the admixture must be considered when evaluating traits in this population. ${ }^{11}$ They have outlined that differing frequencies of certain diseases in European populations compared with African and Amerindian populations in the present study. ${ }^{13}$ Unrelated healthy control $(n=200)$ were matched in terms of age, gender and ethnicity with the group of patients enrolled in the study. Written informed consent of each subject was obtained prior to sample collection. The study protocol was approved by the Ethical Research Board from the International Center of Neurological Restoration (Havana, Cuba) according to the guidelines of the national legislation and the Code of Ethical Principles for Medical Research Involving $\mathrm{Hu}-$ man Subjects of the World Medical Association.

Subject characteristics are shown in Table 1 . The mean age of MS patients at onset was $40.01+/-13.09$ years; $71.04 \%$ were woman. This study was approved by the Ethical Research Board from the International Center of Neurological Restoration (Havana, Cuba).

\section{DNA isolation and AIM genotyping}

Genomic DNA was isolated from whole blood using a Wizard Genomic DNA Purification Kit according to the manufacturer's instruction (Promega, Madison, WI, USA). Table 2 shows the 17 AIM analyzed in this study. AIM were identified from previous studies as having large differences in allele frequency (d. 30\%) between Native American, West African, and European ancestral populations. ${ }^{14}$ Genotyping was performed by PCR amplification, using sequence-specific primers (PCR-SSP), as previously described..$^{15}$ Amplification reactions were performed in a final volume of $25 \mu \mathrm{L}$ containing $100 \mathrm{ng}$ of genomic DNA, $1.5-2.0 \mathrm{mmol} / \mathrm{L} \mathrm{MgCl} 2,50 \mathrm{mmol} / \mathrm{L} \mathrm{KCl}, 10 \mathrm{mmol} / \mathrm{L}$ Tris $\mathrm{HCl}, 0.2$ $\mathrm{mmol} / \mathrm{L}$ of each dNTP, $1 \mathrm{mmol} / \mathrm{L}$ of both primers, $10 \%$ DMSO, and 1UTaqDNApolymerase (Promega). All the loci were scored after electrophoresis through agarose gels.

Table 1. Demographic characteristics of study subjects

\begin{tabular}{|r|c|c|}
\hline \multicolumn{1}{|c|}{ Characteristic } & Cases & Controls \\
\hline No. of subjects (n) & 100 & 200 \\
\hline Gender (female \%) & 71.04 & 79,12 \\
\hline Age (mean +/- SD) & $40,01+/-13,09$ & $38,6+/-12$ \\
*Self-identified ethicity (\%) & & \\
White descent & 76 & 72,5 \\
Black descent & 10,6 & 12,5 \\
Mulattos & 13,3 & 15 \\
\hline
\end{tabular}

* Self-identified ethnicity ${ }^{12}$

suggest that those of Spanish descent may be particularly useful for deciphering complex genetic diseases, for instance dementia and multiple sclerosis that have a higher risk in European than in African populations. ${ }^{12}$

The purpose of this study is to assess, for the first time, $\mathrm{DRB}_{1}{ }^{\star}, \mathrm{DQA} 1^{\star}$, and DQB1* alleles among MS Cuban patients to understand the nature of the HLA association with the diseases in our sample. Also, we typed a panel of 17 Ancestral informative markers (AIM) to control possible confounding traits by population stratification.

\section{Material and methods}

Patients and controls

Samples from 100 MS patients with Relapsing Remitting (MS-RR) diagnosed according to McDonald et al., were analyzed

\section{HLA Typing.}

Selected HLA DRB1 and DQ alleles were determined by SSP-PCR as previously described. ${ }^{16,17}$ The selection of these particular alleles was based on previous studies in which they have been reported to be implicated as part of haplotypes conferring the highest risk or protection scores5. ${ }^{18}$ Brief description: DRB1 ${ }^{*}$ 0401-0411-0301-1501-1502 -0101-0103 -0102 -0701-0702-1001 -1101-1104-1401-1404 1403, DQB1* 0602, DQA1* 0301, *0102. A primer pair to amplify the third intron of DRB1 genes was included in each PCR reaction as the internal positive control. These two primers matched non-allelic sequence. ${ }^{17,18}$ All primers were obtained from the Department of oligonucleotide synthesis, at Center of Genetic Engineering and Biotechnology (Havana, Cuba), and used at $0.25 \mu \mathrm{M}$. Amplified products were separated by electrophoresis in $2 \%$ agarose gels containing ethidium bromide after the addition of loading buffer, and visualized using UV illumination. 
Table 2. AIM allelic frequency in the parental populations ${ }^{15}$. AIM allelic frequencies for MS subjects and controls are also shown. Asterisks precede the name of the larger allele.

\begin{tabular}{lccccc}
\hline AIMs & European & West Africans & Amerindian & Cases & Controls \\
\hline GC-*1F & 0.356 & 0.853 & 0.339 & 0.520 & 0.586 \\
\hline AT3*ins & 0.273 & 0.858 & 0.061 & 0,450 & 0.430 \\
\hline LPL*ins & 0.494 & 0.971 & 0.442 & 0.480 & 0.630 \\
\hline APOA1*ins & 0.917 & 0.420 & 0.977 & 0.800 & 0,768 \\
\hline MID154*ins & 0.333 & 0.806 & 0.420 & 0,378 & 0.415 \\
\hline MID187*ins & 0.342 & 0.759 & 0.301 & 0.430 & 0.442 \\
\hline D11S429*T & 0.440 & 0.087 & 0.119 & 0.430 & 0.375 \\
\hline TSC11020*T & 0.921 & 0.487 & 0.137 & 0.830 & 0.824 \\
\hline FY-11ull*T & 0.999 & 0.001 & 1.000 & 0,800 & 0.715 \\
\hline OCA2*A & 0.636 & 0.115 & 0.488 & 0.582 & 0.563 \\
\hline WI-7423*T & 0.517 & 0.000 & 0.058 & 0.516 & 0.340 \\
\hline GS*1S & 0.607 & 0.931 & 0.931 & 0.760 & 0.758 \\
\hline WI-14867*C & 0.558 & 0.976 & 0.418 & 0.620 & 0.571 \\
\hline WI-16857*G & 0.180 & 0.751 & 0.181 & 0.256 & 0.390 \\
\hline PV92*ins & 0.171 & 0.225 & 0.792 & 0.25 & 0,196 \\
\hline CYP19-E2*T & 0.287 & 0.332 & 0.741 & 0,239 & 0.419 \\
\hline TYR 192*A & 0.485 & 0.005 & 0.034 & 0.400 & 0.359 \\
\hline
\end{tabular}

Statistical analysis. The fit of the genotype frequencies to the Hardy-Weinberg proportions was tested by the Chi-square test. Haplotype frequencies were estimated by means of an expectation maximization algorithm. ${ }^{19}$ We used parental population frequencies reported ${ }^{14}$ for samples of Spanish, average of Amerindians (Mayan, southwestern US Native Americans), and average of West Africans (Central African Republic, Nigeria, and Sierra Leone) (Table 2). To test for population stratification, the STRUCTURE 2.1 program ${ }^{19}$ was used. The program was run initially with 70000 iterations for the burn-in period and 100000 additional iterations to obtain parameter estimates, with a prior distribution that allowed $\mathrm{K}$ to take values from 1 to 3 . Additional runs with longer iterations were also carried out to check the consistency of the results. The frequencies of HLA class II was compared between patients and controls using the chi-square test or the two-tailed Fisher's exact probability test. Odds Ratio (OR) (95\% CI) was also estimated (SPSS 16.0 software). The level of significance was taken as $\mathrm{p}$ value $<0.05$. For allele comparisons, Bonferroni's method was used for the correction of multiple comparisons, multiplying the value of $\mathrm{p}$ obtained in the statistical test by the total number of alleles tested. ${ }^{16}$ In order to control potential confounding because of population stratification as a result of admixture, the ADMIXMAP program was used. ${ }^{21}$ This program performs an association analysis by means of a logistic regression for the relation of MS, as the dependent variable, and HLA, introducing individual ancestry estimates as covariates. The admixture proportions of groups were estimated by the gene identity method $^{22}$ using the software Admix 95 kindly provided by Bertoni B (http://www.genetica.fmed.edu.uy/software.htm)
Allele frequencies for the 17 AIMs in ancestral populations, MS, and healthy controls are shown in Table 2. There was no deviation from Hardy-Weinberg proportions ( $p>0.05)$. Genetic ancestry estimates showed that European contribution was preponderant in patients and controls groups, $80.1 \%$ and $76 \%$ respectively. West African estimates reached $16.9 \%$ and Native American $2 \%$ for cases, while West African reached 21.7\% and Native American 2.3\% for controls. The majority of the cohort concentrates to the European component of the European-West African axis with a restricted and almost absent Native American component.

Our results indicate the presence of substructure in the whole sample. The STRUCTURE program consistently assigned individuals to two groups with a higher probability than it did to a single group or three groups. The probability of $\mathrm{K}=2(-4257.7)$ was higher than $K=1(-4350)$ and $K=3(-4365)$, indicating the presence of two distinct clusters

The result of the logistic regression analysis with MS as a dependent variable showed that odds ratio for MS, associated with an unit change in European admixture proportion, was estimated as 5.7 (95\% CI 1.2-36).

The association of selected HLA DR/DQ alleles with MS in the Cuban sample was evaluated. HLA-DRB1 and DQ typing differed significantly between MS patients and controls. The HLADRB1, HLA-DQA1 and DQB1 allelic associations for MS patients and controls are shown (Table 3 ). Evidence for susceptibility to MS was observed for the presence of HLA-DRB1 ${ }^{\star} 15, \mathrm{DRB}^{\star}{ }^{\star} 14$, DQA $1^{*} 01$ and DQB $1^{\star} 06$ alleles, with higher odds ratio (OR) compared to healthy controls (Table 3). A modest protective effect of HLA DRB $1{ }^{\star} 01,{ }^{\star} 07,{ }^{\star} 10$ were found among MS patients (OR 0.35 , $0.2,0.4$ respectively).

After correcting for admixture, a new association to HLA$\mathrm{DRB} 1^{\star} 1101$ was identified, and associations for the alleles above 
Table 3. HLA Allelic association of MS patient's vs controls

\begin{tabular}{|c|c|c|c|c|c|}
\hline HIIA & Alleles & $\begin{array}{l}\text { pvalue } \\
\text { non adjustment } \\
\text { for admixture }\end{array}$ & $\begin{array}{l}p \text { value } \\
\text { adjustment for } \\
\text { admixture }\end{array}$ & $O R$ & $95 \%$ 지 \\
\hline \multirow[t]{9}{*}{ DRB1* } & 0301 & ns & ns & 0.86 & $(0.8-1.5)$ \\
\hline & $1501-1502$ & $<0.01$ & $<0.01$ & 3.40 & $(1.8-6.1)$ \\
\hline & $0101-0103$ & ns & ns & 0.35 & $(0.16-0.92)$ \\
\hline & 0102 & ns & ns & 0.24 & $(0.06-0.8)$ \\
\hline & $0701-0702$ & $<0.01$ & $<0.01$ & 0.21 & $(0.1-0.5)$ \\
\hline & 1001 & ns & ns & 0.47 & $(0.25-0.91)$ \\
\hline & $1101-1104$ & ns & 0.01 & 0.19 & $(0.084-0.441)$ \\
\hline & $1401-1404$ & $<0.01$ & $<0.01$ & 4.96 & $(2.29-10.7)$ \\
\hline & 1403 & ns & ns & 0.86 & $(0.25-2.92)$ \\
\hline \multirow[t]{2}{*}{ DQA1* } & 0301 & ns & ns & 1.25 & $(0.71-2.20)$ \\
\hline & 0102 & $<0.01$ & 0.01 & 2.53 & $(1.48-4.32)$ \\
\hline DQB1* & 0602 & $<0.01$ & $<0.01$ & 2.77 & $(1.57-4.86)$ \\
\hline
\end{tabular}

$O R$, odds ratio; $C I$, confidence interval; $p$ value $<0.05$ corrected for Bonferroni was considered significant; $n s=$ not significant

Table 4. Association analysis of HLA haplotypes with the MS $p$ value adjustment for admixture

\begin{tabular}{llll}
\hline Haplotype & Alleles & $p$ value & OR \\
\hline $\mathrm{DQA1}^{* / \mathrm{DQBI}^{*}}$ & $0102 / 0602$ & 0,003 & 2,2 \\
\hline $\mathrm{DRB1}^{*}$ & $0103 / 0701 / 1001$ & 0,04 & 0,6 \\
\hline $\mathrm{DRBI}^{*} / \mathrm{DQA1} / \mathrm{DQB1}$ & $1501 / 0102 / 0602$ & $1,3 \times 10^{-5}$ & 3,8 \\
\hline $\mathrm{DRBI}^{*} / \mathrm{DQA1}^{*} / \mathrm{DQBI}^{*}$ & $1501-0103-0701-1001 / 0102 / 0602$ & $0,6 \times 10^{-3}$ & 3,22 \\
\hline
\end{tabular}

$p$ value $<0.05$ corrected for Bonferroni was considered significant

described before admixture correction $(\mathrm{p}<0.01)$ remained significant.

The disease association at the level of four-loci haplotypes was carried out (Table 4). DQA1 ${ }^{\star} 0102 / \mathrm{DQB1}{ }^{\star} 0602(\mathrm{p}<0.003)$; DRB1* 1501/ DQA1* 0102/ DQB1*0602 and DRB1* 1501-0103-0701$1001 / \mathrm{DQA} 1^{\star} 0102 / \mathrm{DQB1}{ }^{\star} 0602\left(0.6 \times 10^{-3}\right)$ have odds ratios $2.2,3.8$ and 3.22 respectively, whereas DRB1 ${ }^{\star} 0103 /{ }^{*} 0701 /{ }^{\star} 1001(\mathrm{p}<0.04)$ has OR 0.6. These associations remained significant after correcting for admixture.

\section{Discussion}

MS is a complex autoimmune disease with over 100 confirmed associated genes or genetic loci and a low increasing number of confirmed environmental risk factors. ${ }^{5}$ The strongest genetic predisposition correlates with the major histocompatibility complex, class II, DR beta 1 (HLA-DRB1 ${ }^{\star} 1501$ allele) with some contribution from other alleles. ${ }^{5}$
We report that HLA-DRB1 and DQ typing significantly differed between MS patients and controls. Evidence for susceptibility to MS was observed with the presence of HLA-DRB1 ${ }^{\star} 15$, $\mathrm{DRB} 1^{\star} 14, \mathrm{DQA} 1^{\star} 01$ and $\mathrm{DQB} 1^{\star} 06$ alleles with higher odds ratio (OR) compared to healthy controls (Table 3). Diaz-Horta et al reported before an opposite association for diabetic Cuban patients. ${ }^{23}$ Modest protective effects of HLA DRB1 ${ }^{\star} 01, \mathrm{DRB} 1^{\star} 07$, $\mathrm{DRB} 1^{\star} 10$ were found among MS patients (OR 0.37, 0.2, 0.4 respectively).

Several genetic studies have described HLA-DRB1*1501 as the main susceptibility allele in MS6. Dyment et al., later considered the importance of taking into account that some haplotypes or loci other than HLA-DRB ${ }^{\star} 15$ contribute to MS risk 24 . However, a recent genome wide association study 5 that includes 9,772 MS patients and 1700 controls showed that DRB1* 1501 has the strongest association with MS with a $p$ value of $1 \times 10-320$. Our results agree with this report. 
Other studies examined the role of ethnicity or ancestry in MS epidemiology ${ }^{7.25}$ A relatively high prevalence of MS is found in Western Europe and North America. In Europe the prevalence ranges from 10 to 187 per 100000 with a higher rate in northern countries. ${ }^{26}$ In addition, a strong association between the HLA$\mathrm{DRB1}^{\star} 15$ allele and MS has been shown in studies of northern Europeans and their descendants. ${ }^{27}$

The Cuban population is essentially a result of the mixture between Spanish, West Africans, and to a lesser degree, Amerindian tribes that inhabited the island. ${ }^{28}$ Cintado et al., defined a population structure in a multiethnic Cuban population from Havana City and reported $85 \%$ of Spanish European descent. ${ }^{11}$

A typing of 17 markers having large differences in frequencies between European, West African and Native American populations was applied to the present study to associate ancestry proportions with respect to MS. We observed that European contributions predominate in patients that are mainly white (76\%), with an estimated OR (odds ratio) of 5.7, with a wide-range confidence interval (CI 1.2-36).

Similar estimates were reported for MS patients in Brazil, also a country with a highly mixed population. According to the Brazilian study MS had a high prevalence within whites with Western Europe ancestry. ${ }^{10}$ In Cuba, in respect to another autoimmune disease, it was confirmed that T1DM was associated with a preponderant genome proportion of European ancestry after ADMIXMAP evaluation. ${ }^{23}$

Toro et al have been studied the low prevalence of MS in Bogota, Colombia which present highly admixed population and have reported that HLADRB1* 15 allele confers susceptibility to MS whereas HLA-DRB1 ${ }^{\star} 14$ allele exerted resistance to disease. ${ }^{29}$

Results from the present study have defined another allele, HLA-DRB ${ }^{\star} 1101$, associated to the disease, mainly in Caucasian patients. These outcomes confirm the importance of ancestry evaluation as a robust tool to adjust for population admixture, which controls population stratification and greatly avoids false associations in case-control studies. ${ }^{30}$ The distribution and diversity of $\mathrm{DRB} 1^{\star} 11$ alleles varies among populations. DRB1 ${ }^{\star} 1101$ has been described as the predominant allele, while HLA DRB1 ${ }^{\star} 1104$ is the second most frequent allele, as stated by a previous study that included Caucasian, Asian/Pacific Islanders, Hispanics and Native Americans. ${ }^{31}$

Even more, HLA-DRB1 ${ }^{\star} 1101$ is part of certain allele groups defined for their association to MS risk, ${ }^{7,32}$ which is formed by the alleles DRB1 $1^{\star} 03, \mathrm{DRB} 1^{\star} 14, \mathrm{DRB} 1^{\star} 07$ and $\mathrm{DRB} 1^{\star} 11$. However in the present study this allele was associated to disease protection, a result that corresponds to reports from others authors ${ }^{33}$ which have found that HLA-DRB1 ${ }^{\star} 14$ and HLA-DRB $1^{\star} 11$ bearing haplotypes are protective with OR 0.75 and 0.55 respectively. In that sense Ramagopalan et al., using a Canadian dataset confirmed that HLA DRB1*11 bearing haplotypes are novel and statistically significant resistance haplotypes. ${ }^{34}$ They also defined that this allele shows a multiplicative mode of inheritance. According to these authors the protective effect of HLA DRB $1^{*} 11$ over HLA$\mathrm{DRB}^{\star}{ }^{1} 15$ appears to be weaker than the effect of HLA -DRB1 ${ }^{\star} 14$, but both alleles reduce risk associated with HLA-DRB1*17. Dominant variants on HLA-DRB1 ${ }^{\star} 14$ and HLA-DRB1 ${ }^{\star} 11$ haplotypes can generate $\mathrm{T}$ cells that suppress autoreactive $\mathrm{T}$ cells, even those generated by HLA-DRB1* 15 .

Additionally a strong association of MS and haplotype $\mathrm{DRB}^{\star} 1501, \mathrm{DQA} 1^{\star} 0102, \mathrm{DQB} 1^{\star} 0602$ was observed in patients included in the present study (Table 4 ). This result corresponds to the previous repeatedly confirmed association of HLA class II $\mathrm{DRB1}^{\star} 1501 / \mathrm{DQA} 1^{\star} 0102, \mathrm{DQB1}^{\star} 0602(\mathrm{DR} 2)$ region with $\mathrm{MS}$ for most Caucasians haplotypes. ${ }^{35}$ Dayment et al., have been fine mapped this haplotype in the North European population and they have estimated risk ratios of approximately 3 , and homozygosity for this haplotype increases MS risk sixfold. ${ }^{6}$ Interestingly a risk-associated haplotype to MS in our patient sample was previously identified as protective for T1DM also among Cuban patients, ${ }^{23}$ which agrees with other reports of patients with European ancestry suffering from these autoimmune diseases.

\section{Acknowledgements}

The authors wish to thank the multiple sclerosis patients and the healthy controls that participated in this study. The authors express their acknowledgement to Dr Eduardo Penton and Miriam Ribas for their assistance with language corrections.

\section{Referencias bibliográficas}

1. Eichhrost H.. Veber infantile und Hereditare multiple sklerose. Arch Pathol anat Physiol; Klin Med 146 (1896) 173-192

2. Jersild C., Svejgaard A., Fog T. HL-A antigens and multiple sclerosis. Lancet. 1 (1972) 1240-1241

3. Jersild C, Fog T, Hansen GS, Thomsen M, Svejgaard A, et al. Histocompatibility determinants in multiple sclerosis, with special reference to clinical course. Lancet 2 (1973) 1221-1225

4. Lincoln MR, Ramagopalan SV, Chao MJ, et al. Epistasis among HLADRB1, HLA-DQA1, and HLA-DQB1 loci determines multiple sclerosis susceptibility. Proc Natl Acad Sci USA. 106 (2009) 7542-7547

5. International Multiple Sclerosis Genetics Consortium (IMSGC) et al. Genetic risk and a primary role for cell-mediated immune mechanisms in multiple sclerosis. Nature 476 (2011) 214-219

6. Dyment DA, Ebers GC, Sadovnick AD. Genetics of multiple sclerosis. Lancet Neurol. 3 (2004) 104-110

7. Rosati G. The prevalence of multiple sclerosis in the world: An update. Neurol Sci 22 (2001) 117-139

8. Cabrera-Gomez JA. Esclerosis multiple en Cuba: Epidemiologia, genetica y aspectos clinicos. In: Arriagada C and Nogales-Gaete J (Eds) Esclerosis Multiple: una mirada Ibero-Panamericana. 2ND ed. Santiago de Chile. Demos Medical Publishing. (2008) 169-182

9. World Health Organization: Atlas multiple sclerosis resources in the world. Geneva 2008: WHO Press

10. Brum DG., Luizon MR., Santos AC, Lana-Peixoto MA, Rocha CF et al. European ancestry predominates in Neuromyelitis Optica and Multiple Sclerosis patients from Brazil. PloS ONE 8 (2013) e58925

11. Cintado A, Companioni O, Nazabal M, Camacho H, Ferrer A, Fernandez de Cossio M. E, Marrero A. et al. Admixture estimates for the population of Havana City. Annals of Human Biology. 36 (2009) 350-360

12. Halder I and Shriver MD. Measuring and using admixture to study the genetics of complex disease. Hum Genomics. 1 (2003) 52-62

13. McDonald WI, Compston A, Edan G, Goodkin D, Hartung HP, Lublin FD, McFarland HF. et al. Recommended Diagnostic Criteria for Multiple Sclerosis: Guidelines from the International Panel on the Diagnosis of Multiple Sclerosis. Annals of Neurology. 50 (2001) 121127

14. Bonilla C, Parra EJ, Pfaff CL, Dios S, Marshall JA, Hamman RF, Ferrell RE, et al. Admixture in the Hispanics of the San Luis Valley, Colorado, and its implications for complex trait gene mapping. Ann Hum Genet. 68 (2004) 139-153

15. Bonilla C, Gutierrez G, Parra EJ, Kline C, Shriver MD. Admixture analysis of a rural population of the State of Guerrero, Mexico. Am J Phys Anthropol. 128 (2005) 861-869

16. Olerup O, Zetterquist H. HLA-DR typing by PCR amplification with sequence-specific primers (PCR-SSP) in 2 hours: An alternative to serological DR typing in clinical practice including donor-recipient matching in cadaveric transplantation. Tissue Antigens. 39 (1992) 225-235

17. Olerup O, Alder A, Fogdell A. HLA-DQB1 and DQA1 typing by PCR amplification with sequence-specific primers (PCR-SSP) in two hours. Tissue Antigens. 41 (1993) 119

18. Chao MJ, Ramagopalan SV, Herrera BM, Orton SM, Handunnetthi L, Lincoln MR, Dyment DA. et al. MHC transmission: insights into gender bias in MS susceptibility. Neurology. 76 (2011) 242-246

19. Excoffier L, Slatkin M. Maximum-likelihood estimation of molecular haplotype frequencies in a diploid population. Mol Biol Evol. 5 (1995) 921-927

20. Pritchard JK, Stephens M, Donnelly P. Inference of population structure using multilocus genotype data. Genetics 155 (2000) 945-959

21. Hoggart CJ, Parra EJ, Shriver MD, Bonilla C, Kittles RA, Clayton DG, McKeigue PM. Control of confounding of genetic associations in stratified populations. Am J Hum Genet. 72 (2003) 1492-1504

22. Chakraborty R. Estimation of race admixture a new method. Am J Phys Anthropol. 42 (1975) 507-511. 
23. Diaz-Horta O, Cintado A, Fernandez-De-Cossio ME, Nazabal M, Ferrer A, Roca J, Camacho H. et al. Relationship of type 1 diabetes to ancestral proportions and HLA DR/DQ alleles in a sample of the admixed Cuban population. Annals of Human Biology. (2010) 1-11

24. Dyment DA, Herrera BM, Cader MZ, Willer CJ, Lincln MR, Sadovnick AD, Risch N and Eberrs C. Complex interactions among MHC haplotypes in multiple sclerosis: susceptibility and resistance. Hum Mol Genet. 14 (2005) 2019-2026

25. Melcon MO, Melcon CM, Bartoloni LCE, Duran JC, Grzesiuk AK et al. Towards establishing MS prevalence in Latin America and The Caribbean Multiple Sclerosis Journal.19 (2012)145-152

26. Borisow N, Doring A, Pfueller CF, Paul F, Dorr J, Hellwig K. Expert recommendations to personalization of medical approaches in treatment of multiple sclerosis: an overview of family planning and pregnancy. EPMA J. 3 (2012) 9

27. Alvarado-de la Barrera C, Zuniga-Ramos J, Ruis-Morales JA, Estanol B, Granados J and Llorente L. HLA class II genotypes in Mexican Mestizos with familial and non-familial multiple sclerosis. Neurology. 55 (2000)1897-1900

28. Guanche J. Componentes étnicos nación cubana. Colección la fuente viva, Fundación Fernando Ortiz . Ediciones Unión 1996; La Habana, Cuba.

29. Toro J, Cuellar-Giraldo D, Díaz-Cruz C, Burbano LE, et al.HLA-
$\mathrm{DRB}^{\star}{ }^{\star} 14$ is a protective allele for multiple sclerosis in an admixed Colombian population. Neurol Neuroimmunol Neuroinflamm. 3 (2016) e192; doi: 10.1212/NXI.0000000000000192.

30. Enoch MA, Shen PH, Xu K, Hodgkinson C, Goldman D. Using ancestry-informative markers to define populations and detect population stratification. J. Psychopharmacol. 20 (2006) 19-26

31. Tang TF, Huang AY, Pappas A, Slack R, Ng J, Hartzman RJ and Hurley CK Relative frequencies of DRB1 ${ }^{\star} 11$ alleles and their DRB3 associations in five major population groups in a United States bone marrow registry. Human Immunology. 61 (2000) 820-827

32. Wu JS, James I, Wei Q, Castley A, Christiansen FT, et al. Influence of HLA-DRB1 allele heterogeneity on disease risk and clinical course in a West Australian MS cohort: a high-resolution genotyping study. Mult Scler. 16 (2010) 526-532

33. Mescheriakova JY, Kreft KL and Hintzen RQ. Genetics of Multiple Sclerosis. Chapter 10, T. Yamamura, B. Gran (eds.), NewYork Multiple Sclerosis Immunology. 197 (2013) 6-10

34. Ramagopalan SV, Morris AP, Dyment DA, Herrera BM, DeLuca $\mathrm{GC}$, et al. The inheritance of resistance alleles in multiple sclerosis. PLoS Genet. 3 (2007) 1607-1613Int. J. Gynecol. Cancer 16, 71-6

35. Kenealy SJ, Pericak -Vance MA, Hines JL: The genetic epidemiology of multiple sclerosis. J. Neuroimmunol. 143 (2003) 7-12

Recibido: 1 noviembre 2016

Aprobado: 7 diciembre 2016 